\title{
SOME EFFECTS OF DECREASED PLASMA SODIUM CONCENTRATION ON THE COMPOSITION AND TENSION OF THE AQUEOUS HUMOUR*
}

\author{
BY \\ D. F. COLE \\ Ophthalmological Research Unit, Institute of Ophthalmology, University of London
}

THE relationship between the intra-ocular pressure (I.O.P.) and the osmotic concentration of the plasma has been recognized for a considerable time. Hertel (1914) and Weekers (1924) observed an increase of I.O.P. after infusion of hypotonic solutions, and Hertel (1914) also observed that the total water in the contents of the eye increased. Hertel also showed a decrease of I.O.P. after infusion of hypertonic solutions, a finding confirmed by later workers. These facts made it reasonable to suppose that the I.O.P. and the volume of the aqueous humour depended in a simple fashion upon the osmotic gain or loss of water by the eye according as the body fluids in its immediate environment were hypo- or hyper-tonic. In confirmation of this, the enucleated eye was found to behave in a similar fashion (Duke-Elder, 1926; 1932). The present-day notion that the aqueous humour is, at least in part, the result of an active transfer process occurring in the ciliary membrane has caused attention to be directed to the nature of this process and to factors which modify it. Nevertheless, the relationship between aqueous formation and plasma osmotic activity can also be important in determining the rate of flow of aqueous and merits more detailed study. Since the sodium ion, by virtue of its high concentration and of its mainly extracellular location, plays a major part in the osmotic balance of the body fluids, the present experiments were designed to investigate the changes in I.O.P. and in the chemical composition of the aqueous humour in response to reductions in plasma sodium concentration brought about by a variety of different procedures. In some of these procedures both the sodium concentration and the osmolarity of the plasma were decreased whilst in others the osmolarity was kept constant.

\section{Methods and Materials}

Animals.-All experiments were performed on adult rabbits of the New Zealand White strain weighing between 2 and $3 \mathrm{~kg}$. Before use the animals were fed on Diet 18 (Blue Cross Animals Foodstuffs, Associated London Flour Millers Ltd.), and allowed free access to water.

All the experiments, except those in which isotonic glucose was given intraperitoneally, were carried out under general anaesthesia. The anaesthetic used was

* Received for publication June 9, 1958. 
urethane, given by intravenous injection as a 25 per cent. (w/v) solution in 0.9 per cent saline at a dose level of $1.75 \mathrm{~g}$. $/ \mathrm{kg}$. body weight.

Experiments conducted on anaesthetized animals fall into four groups:

(i) Intravenous infusion of isotonic mannitol after nephremphraxis;

(ii) Intravenous infusion of half-isotonic saline-bicarbonate solution after nephremphraxis;

(iii) Intravenous infusion of half-isotonic saline-bicarbonate solution plus intracarotid infusion of 2,4: di-nitrophenol (DNP) after nephremphraxis;

(iv) Nephremphraxis alone.

The last group served as a control, and the results from these four groups were intended to show the changes caused by the various infusions during anaesthesia and after nephremphraxis.

The changes caused by intraperitoneal injection of isotonic glucose were studied in unanaesthetized animals.

(A) The experiments on the four groups of anaesthetized animals had the following procedures in common: After inducing anaesthesia, the abdomen was opened and both renal pedicles tied, the abdominal wound being closed with clips. A cannula connected to a mercury manometer for blood-pressure determination was tied in the left femoral artery, and a No. 1 polythene cannula (O.D. $=0.94 \mathrm{~mm}$; I.D. $=0.74 \mathrm{~mm}$ ), placed in the right femoral vein. The right femoral artery was exposed and cleaned, the more easily to obtain arterial blood samples. 1 per cent. amethocaine B.P. was instilled into each eye and the I.O.P. measured with a Schiötz tonometer (Dixey, London), using a $5.5 \mathrm{~g}$. weight. When the I.O.P. and arterial blood pressure had remained steady for $15 \mathrm{~min}$. after the operation, a sample of arterial blood was withdrawn under paraffin oil and samples of posterior and anterior chamber aqueous taken from one eye. Posterior chamber aqueous was withdrawn into thick-walled capillaries with No. 22 needles sealed into one end, as described by Kinsey (1953); anterior chamber fluid was drawn into a 1-ml. tuberculin syringe with a Luer-lock fitting, under paraffin oil. Providing that the I.O.P. in the other eye remained steady for $5 \mathrm{~min}$. the infusion was then started, except for animals in the fourth group which received no infusion.

Once the infusion had commenced, arterial blood pressure and I.O.P. in the intact eye were recorded every 15 min. until the experiment ended 3 hours later, when samples of aqueous from the intact eye were withdrawn as described above, and a final arterial blood sample was obtained. In some cases intermediate samples of arterial blood were obtained, and in others the experiment was terminated in less than 3 hours.

As soon as the animal had been killed, the eye used in the experiment was connected to a saline reservoir by polythene tubing and a No. 15 needle was inserted into the anterior chamber along the track of the needle used to collect the aqueous. By altering the height of the reservoir above the eye, the Schiötz tonometer was calibrated for known values of I.O.P., a stopcock between the eye and the reservoir being closed whilst the tonometer readings were taken.

Animals, other than those in the control group, were also subjected to the following treatments: 
Mannitol Infusions.-A 5 per cent. (w/v) of mannitol was made up on the morning of the experiment and a total of $60 \mathrm{ml} . / \mathrm{kg}$. body weight was infused intravenously during a period of 5 to $10 \mathrm{~min}$.

Half-Isotonic Saline Infusions.-A stock solution containing 3.8 per cent. (w/v) sodium chloride and 1.01 per cent $(\mathrm{w} / \mathrm{v})$ sodium bicarbonate was prepared beforehand; this was diluted $1: 10$ and adjusted to $\mathrm{pH} 7 \cdot 4$ by addition of $0 \cdot 1 \mathrm{~N}$ hydrochloric acid. The solution was placed in a reservoir about 1 metre above the animals in order to give a sufficient head of pressure for intravenous infusion. During the first 20 to $30 \mathrm{~min}$. the rate of infusion was approximately $4.0 \mathrm{ml} . / \mathrm{min} . / \mathrm{kg}$. body weight, and during the remainder of the experimental period the infusion was continued at $0.3 \mathrm{ml} . / \mathrm{min} . / \mathrm{kg}$. body weight. (Preliminary tests had shown that these rates of infusion usually caused the sodium concentration of the plasma to decrease by 25 to $30 \mathrm{mEq} / \mathrm{l}$. during the first half hour, and thereafter to remain reasonably steady for 3 to 4 hours.)

2,4: Dinitrophenol.-An isotonic solution containing $40 \mathrm{mM} / 1.2,4$ : dinitrophenol (DNP) was infused into the carotid artery on one side through a cannula inserted in the lingual artery. A midline incision was made, commencing at the symphysis mentis and extending 3 in. caudally, the exposed submaxillary salivary gland being retracted to the side. At the caudal (and deeper) end of the exposed region, the lingual artery and hypoglossal nerve were identified near the posterior horn of the hyoid bone and that part of the artery which ran forwards ventrally towards the submaxillary gland was dissected and cleaned. The vessel was dilated by applying a few drops of 1 per cent amethocaine to the region, and a cannula of No. 00 flexible nylon tubing (mean O.D. $\bumpeq 0.72 \mathrm{mM}$ ) containing heparin solution $(1, / 000$ units $/ \mathrm{ml}$.) was inserted and tied in place so that the tip of the cannula was about $2 \mathrm{~mm}$. from the posterior horn of the hyoid bone. The cannula, which was about 9 in. long, was anchored to the connective tissue near the symphysis mentis, and the wound was closed with clips. The free end of the cannula was connected to a No. 22 hypodermic needle which was itself stoppered with a removable spigot until such time as it was attached to a motor-driven syringe containing the DNP solution. When isotonic saline, instead of DNP solution, was infused through cannulae inserted in this manner, no change in I.O.P. or composition of the aqueous humour was observed.

(B) Unanaesthetized animals given isotonic glucose solution intraperitoneally were treated as follows: The rabbit having been placed in a box with only its head exposed, 1 per cent. amethocaine was instilled into each eye and the I.O.P. was measured with the Schiötz tonometer. The ears of the rabbit were held in the operator's left hand and the head rotated gently until the eye was directed upwards; the tonometer was then applied with the right hand. After two or three readings had been made in this way the animal seemed to become accustomed to the procedure and remained undisturbed during the rest of the experiment. Once accustomed to tonometry, the variance between successive I.O.P. measurements during the control period was not significantly greater than in anaesthetized animals. The mean value for I.O.P. was, however, significantly higher than in the groups which were anaesthetized (Table I). Once steady I.O.P. readings were obtained, blood was withdrawn anaerobically from the central artery of the ear which could be identified by transillumination. Aqueous humour was obtained from the posterior and anterior chambers, as described above, and, care having been taken to use new or freshly sharpened needles in the capillary and syringe, the rabbits did not seem to be discomforted. The I.O.P. of the intact eye remaining unaltered after obtaining the aqueous 
from the control eye, a small "bleb" of Nupercaine was raised on the anterior abdominal wall and a No. 0 serum needle was inserted into the peritoneal cavity through the anaesthetized area. The shank of the needle was connected by "Portex" tubing to a 50-ml. syringe, and the rabbit was replaced in its box. Using a three-way tap and reservoir to refill the syringe, 5 per cent. (w/v) glucose solution at $37^{\circ} \mathrm{C}$. was injected at $100 \mathrm{ml} . / \mathrm{kg}$. body weight (Darrow and Yannet, 1935) over a period of about 5 minutes, after which the intraperitoneal needle was withdrawn. There were no signs of discomfort but a condition of extracellular dehydration resembling surgical shock often developed after 2 or 3 hours, as described by Darrow and Yannet (1935). The I.O.P. of the intact eye was estimated every 15 to $30 \mathrm{~min}$. during the next 6 hours, after which a final blood sample was obtained and the posterior and anterior chamber fluid removed from the intact eye. In most cases blood samples were also taken at different times after the intraperitoneal injection. The tonometer readings were calibrated against known values of I.O.P., as described above, after the animal had been killed.

Chemical Methods.-Blood was centrifuged under paraffin oil as soon as possible after collection, and anterior chamber aqueous was transferred to a small specimen tube under paraffin. Sufficient plasma or aqueous for estimation of $\mathrm{pH}$ and bicarbonate (about $150 \mu \mathrm{l}$. if available) was then removed into a capillary tube connected to a syringe filled with mercury in such a way that the sample was contained in the middle section of the tube between droplets of mercury. Such samples could be stored for several days at $3^{\circ} \mathrm{C}$. without change of $\mathrm{CO}_{2}$ content.

Total $\mathrm{CO}_{2}$ was estimated by the micromanometric method of Natelson (1951). When possible, two estimations using $25 \mu l$. fluid were made, but in some cases duplicate samples of $15 \mu \mathrm{l}$. were used. Standard curves for each series of estimations relating partial pressure of evolved gas and total $\mathrm{CO}_{2}$ content were obtained by analysing standard solutions of sodium carbonate. Bicarbonate was calculated from total $\mathrm{CO}_{2}$ using the conversion tables of Milch, Bane, and Roberts (1957), which assume $\mathrm{pK}$ of carbonic acid $=6 \cdot 10$.

$\mathrm{pH}$ was determined with a glass capillary electrode, as described by Joels and MacNaughton (1957), connected to a Cambridge $\mathrm{pH}$ meter.

Chloride was estimated by titration with $0 \cdot 1 \mathrm{~N}$ silver nitrate, the end-point being determined potentiometrically with a silver/silver chloride electrode and an electronic millivoltmeter. $0.1 \mathrm{ml}$. of a 10 per cent. (w/v) solution of sodium nitrate in $1 \mathrm{~N}$ nitric acid was placed in the titration vessel and $10 \mu \mathrm{l}$. plasma or aqueous added from a constriction pipette. This solution, into which dipped the silver/silver chloride electrode, was connected to a calomel half-cell by a bridge of sodium nitrate solution. Silver nitrate was added from an "Agla" microsyringe, and the potential was plotted against the volume of silver nitrate added. The end-point was taken as being the steepest point on this curve.

Sodium was estimated with an "EEL" flame photometer, $20 \mu \mathrm{l}$. fluid being added to $5 \mathrm{ml}$. water. This was the only substance estimated in the posterior chamber fluid, the sample being expelled from the capillary used to collect it into a small glass cup from which it was drawn into a $20-\mu 1$. constriction pipette. The same constriction pipette was used throughout any one series of estimations and was washed and dried after each measurement. It was also used to dilute standard solutions of $0 \cdot 15 \mathrm{~N}$ and $0 \cdot 10 \mathrm{~N}$ sodium chloride with $5 \mathrm{ml}$. water. 
Mannitol was estimated by the method of Hamburger, Ryckewaert, Duizend, and Argant (1948) and, since the final concentrations were high (about $1.0 \mathrm{~g}$. per cent. in plasma), only $50 \mu \mathrm{l}$. plasma or aqueous were needed. The blank values found for the first plasma sample and the aqueous from the control eye before any mannitol had been given were subtracted from the values found in the final plasma and aqueous samples.

Glucose was estimated by the method of Somogyi (1945a,b) using $20 \mu$ l. plasma or aqueous.

Plasma protein concentration was estimated in some experiments using the specific gravity method of Phillips, van Slyke, Dole, Emerson, Hamilton, and Archibald (1945). Sunderman and Boerner (1949) give the relation between

TABLE

SOLUTE CONCENTRATIONS IN PLASMA WATER AND AQUEOUS HUMOUR, AND

Except for the $\mathrm{pH}$ values, in each case, the mean

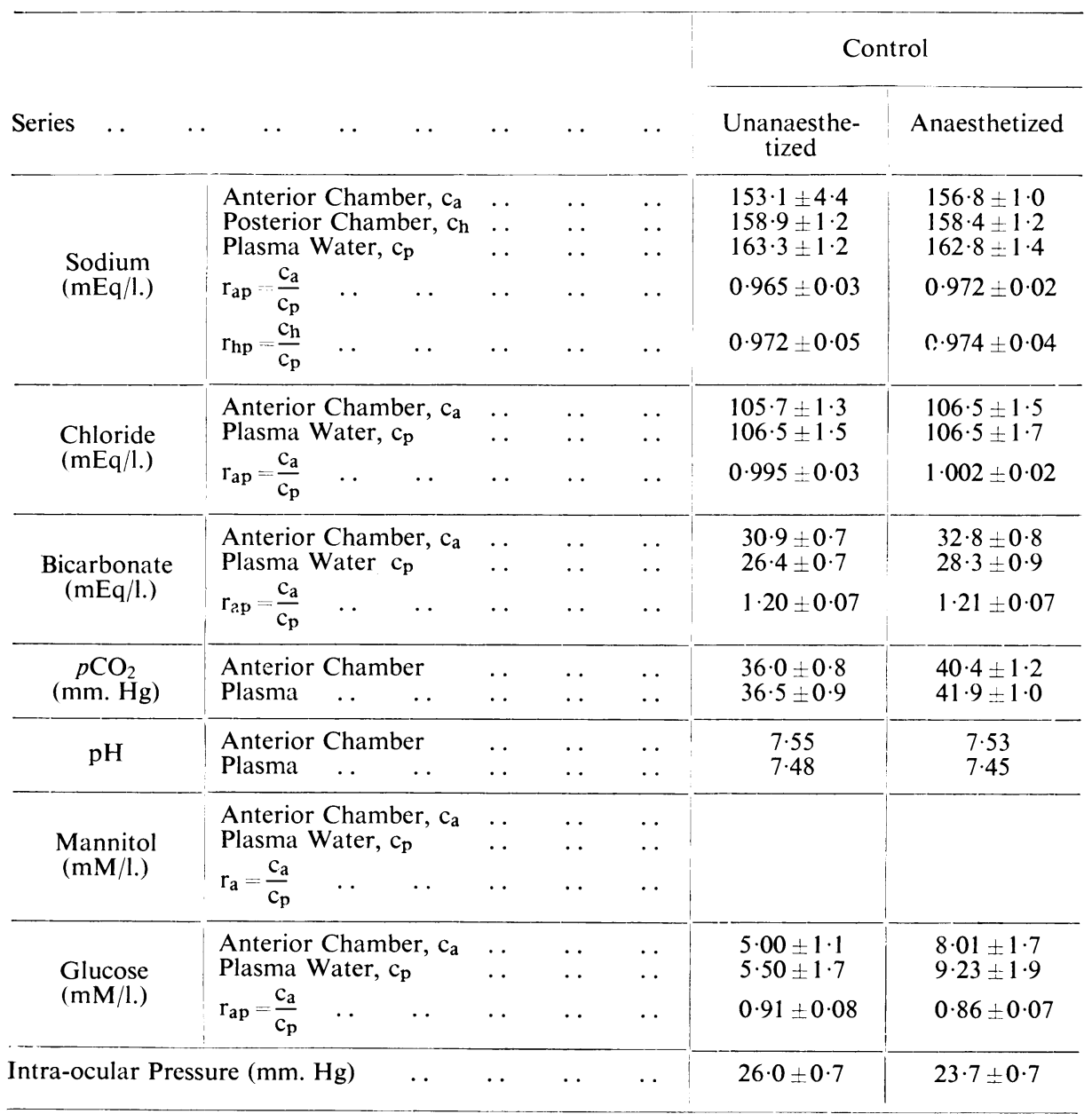


plasma specific gravity $(p)$ and plasma water $(W)$ as; $W=4,225 \cdot 6-3,225 \cdot 6 p$, where $p=\mathrm{g}$. per ml. plasma and $W=\mathrm{g}$. water $/ \mathrm{kg}$.

\section{Results}

On most of the samples of plasma and aqueous it was possible to carry out all the electrolyte estimations described above, and in most cases duplicate values were obtained. In some cases where mannitol was estimated there was only sufficient fluid for determination of sodium. However, each value in the Tables represents a mean derived from at least ten animals. The absolute values for the concentrations in the plasma and aqueous are shown in Table I.

I

INTRA-OCULAR PRESSURE, FROM CONTROL AND EXPERIMENTAL GROUPS and its standard error are shown

\begin{tabular}{|c|c|c|c|c|c|}
\hline \multirow{2}{*}{$\begin{array}{l}\text { Ligation of } \\
\text { Renal Vessels }\end{array}$} & \multirow{2}{*}{$\begin{array}{l}\text { Isotonic } \\
\text { Mannitol }\end{array}$} & \multirow{2}{*}{$\begin{array}{l}\text { Intraperitoneal } \\
\text { Glucose }\end{array}$} & \multicolumn{3}{|c|}{ Hypotonic Saline Infusion } \\
\hline & & & $60 \mathrm{~min}$. & $180 \mathrm{~min}$. & + DNP \\
\hline $\begin{array}{l}157 \cdot 0 \pm 1 \cdot 2 \\
158 \cdot 0 \pm 1 \cdot 2 \\
165 \cdot 0 \pm 1 \cdot 3\end{array}$ & $\begin{array}{l}153 \cdot 1 \pm 2 \cdot 4 \\
151 \cdot 4 \pm 3 \cdot 3 \\
135 \cdot 0 \pm 4 \cdot 1\end{array}$ & $\begin{array}{l}141 \cdot 7 \pm 1 \cdot 8 \\
142 \cdot 5 \pm 1 \cdot 5 \\
139 \cdot 0 \pm 2 \cdot 8\end{array}$ & $\begin{array}{l}138 \cdot 4 \pm 2 \cdot 9 \\
146 \cdot 4 \pm 3 \cdot 7 \\
138 \cdot 6 \pm 3 \cdot 7\end{array}$ & $\begin{array}{l}143 \cdot 4 \pm 3 \cdot 1 \\
143 \cdot 2 \pm 3 \cdot 0 \\
132 \cdot 9 \pm 4 \cdot 2\end{array}$ & $\begin{array}{l}136 \cdot 7 \pm 4 \cdot 7 \\
133 \cdot 9 \pm 2 \cdot 3 \\
125 \cdot 4 \pm 4 \cdot 9\end{array}$ \\
\hline $0.968 \pm 0.04$ & $1 \cdot 141 \pm 0.05$ & $1 \cdot 022 \pm 0 \cdot 03$ & $1.002 \pm 0.03$ & $1.081 \pm 0.03$ & $1.093 \pm 0.05$ \\
\hline $0.959 \pm 0.03$ & $1 \cdot 121 \pm 0.04$ & $1 \cdot 025 \pm 0 \cdot 03$ & $1 \cdot 058 \pm 0 \cdot 04$ & $1.078 \pm 0.04$ & $1.067 \pm 0.05$ \\
\hline $\begin{array}{l}108 \cdot 1 \pm 1 \cdot 3 \\
109 \cdot 5 \pm 1 \cdot 8\end{array}$ & $\begin{array}{l}109 \cdot 6 \pm 4 \cdot 3 \\
85 \cdot 30 \pm 5 \cdot 0\end{array}$ & $\begin{array}{l}97 \cdot 40 \pm 4 \cdot 7 \\
90 \cdot 30 \pm 4 \cdot 2\end{array}$ & $\begin{array}{l}90 \cdot 00 \pm 3 \cdot 7 \\
80 \cdot 70 \pm 4 \cdot 4\end{array}$ & $\begin{array}{l}88 \cdot 3 \pm 5 \cdot 6 \\
79 \cdot 3 \pm 5 \cdot 1\end{array}$ & $\begin{array}{l}93 \cdot 6 \pm 3 \cdot 4 \\
79 \cdot 7 \pm 6 \cdot 9\end{array}$ \\
\hline $0.989 \pm 0.04$ & $1 \cdot 284 \pm 0 \cdot 06$ & $1 \cdot 078 \pm 0 \cdot 05$ & $1 \cdot 123 \pm 0 \cdot 08$ & $1 \cdot 115=0 \cdot 08$ & $1 \cdot 174 \pm 0 \cdot 10$ \\
\hline $\begin{array}{l}28 \cdot 1 \pm 1 \cdot 4 \\
24 \cdot 3 \pm 1 \cdot 5\end{array}$ & $\begin{array}{l}32 \cdot 6 \pm 1 \cdot 2 \\
24 \cdot 8 \pm 1 \cdot 5\end{array}$ & $\begin{array}{l}27 \cdot 9 \pm 1 \cdot 5 \\
20 \cdot 9 \pm 1 \cdot 4\end{array}$ & $\begin{array}{l}27 \cdot 2 \pm 2 \cdot 0 \\
26 \cdot 0 \pm 1 \cdot 8\end{array}$ & $\begin{array}{l}28 \cdot 0 \pm 1 \cdot 8 \\
19 \cdot 6 \pm 2 \cdot 5\end{array}$ & $\begin{array}{l}23 \cdot 9 \pm 1 \cdot 1 \\
16 \cdot 9 \pm 0.9\end{array}$ \\
\hline $1 \cdot 21 \pm 0.07$ & $1.44+0.09$ & $1 \cdot 39 \pm 0.08$ & $1 \cdot 38 \pm 0 \cdot 11$ & $1 \cdot 45 \pm 0.09$ & $1 \cdot 50 \pm 0.09$ \\
\hline $\begin{array}{l}43 \cdot 6 \pm 1 \cdot 8 \\
43 \cdot 3 \pm 1 \cdot 7\end{array}$ & $\begin{array}{l}42 \cdot 5 \pm 1 \cdot 4 \\
42 \cdot 3 \pm 2 \cdot 1\end{array}$ & $\begin{array}{l}47 \cdot 5 \pm 2 \cdot 3 \\
45 \cdot 6 \pm 2 \cdot 1\end{array}$ & $\begin{array}{l}42 \cdot 3 \pm 2 \cdot 2 \\
42 \cdot 4 \pm 2 \cdot 5\end{array}$ & $\begin{array}{l}43 \cdot 5 \pm 2 \cdot 0 \\
44 \cdot 0 \pm 3 \cdot 0\end{array}$ & $\begin{array}{l}45 \cdot 5 \pm 1 \cdot 8 \\
44 \cdot 8 \pm 1 \cdot 7\end{array}$ \\
\hline \multirow[t]{3}{*}{$\begin{array}{l}7 \cdot 43 \\
7 \cdot 37\end{array}$} & $\begin{array}{l}7 \cdot 49 \\
7 \cdot 39\end{array}$ & $\begin{array}{l}7 \cdot 40 \\
7 \cdot 30\end{array}$ & $\begin{array}{l}7 \cdot 43 \\
7 \cdot 41\end{array}$ & $\begin{array}{l}7 \cdot 43 \\
7 \cdot 27\end{array}$ & $\begin{array}{l}7 \cdot 35 \\
7 \cdot 20\end{array}$ \\
\hline & $\begin{array}{r}8 \cdot 69 \pm 2 \cdot 1 \\
65 \cdot 91 \pm 4 \cdot 1\end{array}$ & & & & \\
\hline & $0 \cdot 145 \pm 0 \cdot 04$ & & & & \\
\hline $\begin{array}{r}8 \cdot 76 \pm 2 \cdot 1 \\
10 \cdot 11 \pm 3 \cdot 2\end{array}$ & & $\begin{array}{l}13 \cdot 10 \pm 2 \cdot 5 \\
14 \cdot 24 \pm 2 \cdot 8\end{array}$ & $\begin{array}{r}6 \cdot 10 \pm 2 \cdot 3 \\
10 \cdot 32 \pm 4 \cdot 7\end{array}$ & $\begin{array}{r}5 \cdot 13 \pm 1 \cdot 1 \\
13 \cdot 51 \pm 4 \cdot 9\end{array}$ & $\begin{array}{r}5 \cdot 20 \pm 1 \cdot 3 \\
12 \cdot 41 \pm 3 \cdot 2\end{array}$ \\
\hline $0 \cdot 86 \pm 0 \cdot 09$ & & $0.92 \pm 0.09$ & $0.59 \pm 0.09$ & $0 \cdot 38 \pm 0 \cdot 10$ & $0.42 \pm 0.09$ \\
\hline $23 \cdot 5 \pm 0 \cdot 7$ & $20 \cdot 5 \pm 1 \cdot 4$ & $29 \cdot 9 \pm 0 \cdot 8$ & $26 \cdot 2 \pm 0 \cdot 6$ & $25 \cdot 9 \pm 0 \cdot 4$ & $17 \cdot 2 \pm 0 \cdot 7$ \\
\hline
\end{tabular}


TABLE

CHANGES RESULTING FROM INFUSION OF MANNITOL, OF HYPOTONIC SALINE, AND

In each case the mean change and

\begin{tabular}{|c|c|c|c|c|}
\hline Series & .. & .. & Mannitol Infusion & $\begin{array}{l}\text { Intraperitoneal } \\
\text { Glucose }\end{array}$ \\
\hline Sodium & 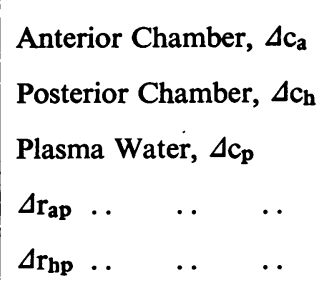 & $\begin{array}{l}\cdots \\
\cdots \\
\cdots \\
\cdots \\
\cdots\end{array}$ & 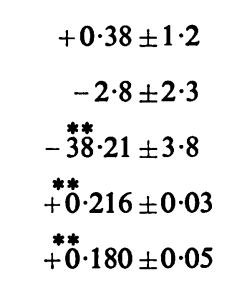 & 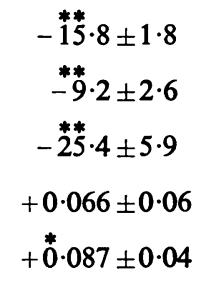 \\
\hline Chloride & $\begin{array}{l}\text { Anterior Chamber, } \Delta \mathrm{c}_{\mathbf{a}} \\
\text { Plasma Water, } \Delta \mathrm{c}_{\mathrm{p}} \ldots \\
\Delta \mathrm{r}_{\mathrm{ap}} \ldots \quad \ldots \quad \ldots\end{array}$ & $\begin{array}{l}\cdots \\
\cdots \\
.\end{array}$ & $\begin{array}{c}-4 \cdot 9 \pm 4 \cdot 8 \\
-29 \cdot 1 \pm 3 \cdot 7 \\
+0 * 282 \pm 0 \cdot 05\end{array}$ & $\begin{array}{l}-16 \cdot 8 \pm 3 \cdot 3 \\
-16 * \\
-26 \cdot 6 \pm 4 \cdot 6 \\
\stackrel{* *}{*}+171 \pm 0 \cdot 04\end{array}$ \\
\hline Bicarbonate & $\begin{array}{l}\text { Anterior Chamber, } \Delta \mathrm{c}_{\mathrm{a}} \\
\text { Plasma Water, } \Delta \mathrm{c}_{\mathrm{p}} . . \\
\Delta \mathrm{r}_{\mathrm{ap}} \ldots \quad \ldots \quad . .\end{array}$ & $\begin{array}{l}\cdots \\
\cdots \\
.\end{array}$ & $\begin{array}{c}-0.77 \pm 1 \cdot 1 \\
-5 \cdot 5 \pm 2 \cdot 1 \\
+* * \\
+0 \cdot 242 \pm 0.05\end{array}$ & 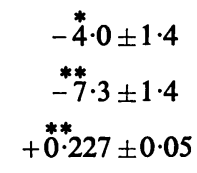 \\
\hline $\begin{array}{l}\Delta \text { I.O.P. } \quad . \\
\Delta \text { I.O.P. after D }\end{array}$ & $\begin{array}{l}. . \\
. .\end{array}$ & .. & $\begin{array}{c}\stackrel{* *}{-5 \cdot 7} \pm 00 \cdot 8 \\
-\end{array}$ & $\begin{array}{c}* * \\
+3 \cdot 5 \pm 0 \cdot 7 \\
-\end{array}$ \\
\hline
\end{tabular}

Values differing significantly from zero are indicated by asterisks; thus

As there is considerable variation in the control value between one animal and another, a more satisfactory picture is obtained from the changes which occurred in individual animals as a result of the experimental procedures. The mean values of these changes are shown in Tables II and III.

Table IV (overleaf) gives values for the sum of the concentration differences of sodium, chloride, and bicarbonate between aqueous and plasma water compared with the concentration difference of glucose or mannitol.

Table V (overleaf) shows correlation coefficients between blood pressure and I.O.P. in each group and the regression coefficient of I.O.P. upon blood pressure. Only in the animals given isotonic mannitol is there a significant correlation. The mean changes in I.O.P. at 15-minute intervals (in some cases calculated by interpolation) are shown in Figs 1 to 4, where each vertical line represents twice the standard error of the mean at that particular point.

When describing and discussing the aqueous humour dynamics, it was found convenient to adopt the symbols suggested by Duke-Elder and Maurice(1957). 
II

INTRAPERITONEAL INJECTION OF GLUCOSE, INFUSION ADMINISTRATION OF DNP

its standard error are given

\begin{tabular}{|c|c|c|c|}
\hline \multicolumn{3}{|c|}{ Hypotonic Saline Infusion } & \multirow{2}{*}{$\begin{array}{l}\text { Ligation of Renal } \\
\text { Vessels }\end{array}$} \\
\hline $60 \mathrm{~min}$. & $180 \mathrm{~min}$. & + DNP & \\
\hline$-26 \cdot 2 \pm 3 \cdot 5$ & $-\stackrel{* *}{16} \cdot 1 \pm 1 \cdot 9$ & $-19 * 8 \pm 2 \cdot 4$ & $+0.25 \pm 1 \cdot 1$ \\
\hline$-\stackrel{* *}{23} \cdot 6 \pm 4 \cdot 5$ & $-\stackrel{* *}{17} \cdot 5 \pm 2 \cdot 4$ & $-\stackrel{* *}{24} \cdot 7 \pm 3 \cdot 5$ & $-0 \cdot 37 \pm 1 \cdot 5$ \\
\hline$-\stackrel{* *}{30} \cdot 9 \pm 5 \cdot 9$ & $-\stackrel{* *}{28} \cdot 7 \pm 4 \cdot 8$ & $-31 \cdot 1 \pm 5 \cdot 6$ & $+2 \cdot 21 \pm 1 \cdot 7$ \\
\hline$+0.044 \pm 0.02$ & $\stackrel{* *}{+0.125 \pm 0.03}$ & $\stackrel{* *}{+0} \cdot 165 \pm 0.03$ & $-0.009 \pm 0.02$ \\
\hline$+0.042 \pm 0.03$ & $+0.060 \pm 0.04$ & $+\stackrel{*}{0} \cdot 119 \pm 0.05$ & $-0.012 \pm 0.03$ \\
\hline$-13 \cdot 8 \pm 4 \cdot 6$ & $-{ }^{*} 13 \cdot 9 \pm 5 \cdot 6$ & $\stackrel{* *}{-8 \cdot 4} \pm 2 \cdot 3$ & $+1 \cdot 7 \pm 3 \cdot 5$ \\
\hline$-\stackrel{* *}{24} \cdot 0 \pm 4 \cdot 7$ & $-\stackrel{* *}{22} \cdot 4 \pm 1 \cdot 8$ & $-22 \cdot 0 \pm 6 \cdot 5$ & $+3 \cdot 0 \pm 2 \cdot 7$ \\
\hline$+0.110 \pm 0.07$ & $+0.080 \pm 0.06$ & $+\stackrel{* *}{0 \cdot 264} \pm 0.05$ & $-0.010 \pm 0.08$ \\
\hline$-0 \cdot 70 \pm 1 \cdot 3$ & $\stackrel{* *}{-5 \cdot 6 \pm 1 \cdot 3}$ & $\stackrel{* *}{-6.6} \pm 0.9$ & $\stackrel{* *}{-4.0} \pm 0.9$ \\
\hline$-\stackrel{*}{2} \cdot 6 \pm 0 \cdot 9$ & $\stackrel{* *}{-7} \cdot 5 \pm 1 \cdot 0$ & $\stackrel{* *}{-7} \cdot 6 \pm 0.6$ & $\stackrel{* *}{-3} \cdot 7 \pm 0 \cdot 8$ \\
\hline$+\stackrel{*}{0} \cdot 200 \pm 0.07$ & $+\stackrel{*}{0} \cdot 259 \pm 0.09$ & $+\stackrel{*}{0} \cdot 289 \pm 0 \cdot 10$ & $-0.012 \pm 0.70$ \\
\hline$+\stackrel{* *}{5} \cdot 1 \pm 0 \cdot 4$ & $\begin{array}{r}* * \\
+4 \cdot 7 \pm 0 \cdot 8\end{array}$ & - & $-0 \cdot 2 \pm 0 \cdot 5$ \\
\hline - & & $\stackrel{* *}{-9} \cdot 8 \pm 0.8$ & - \\
\hline
\end{tabular}

the range, $0.05>P>0.01$ is shown by ${ }^{*}$ and the range $0.01>P$ by ${ }^{* *}$.

TABLE III

CHANGES IN pH AND $\mathrm{pCO}_{2}$ CAUSED BY INFUSION OF MANNITOL, INTRAPERITONEAL INJECTION OF GLUCOSE, INFUSION OF HYPOTONIC SALINE, AND ADMINISTRATION OF DNP

Except for the $\mathrm{pH}$ values, the mean change and its standard error are given

\begin{tabular}{|c|c|c|c|c|c|c|c|}
\hline \multirow{2}{*}{ Series } & \multirow{2}{*}{$\cdots$} & \multirow{2}{*}{$\begin{array}{l}\text { Isotonic } \\
\text { Mannitol } \\
\text { Glucose }\end{array}$} & \multirow{2}{*}{$\begin{array}{c}\text { Intraperi- } \\
\text { toneal }\end{array}$} & \multicolumn{3}{|c|}{ Hypotonic Saline Infusion } & \multirow{2}{*}{$\begin{array}{c}\text { Ligation } \\
\text { of Renal } \\
\text { Vessels }\end{array}$} \\
\hline & & & & $60 \mathrm{~min}$. & $180 \mathrm{~min}$. & + DNP & \\
\hline $\mathrm{pH}$ & $\begin{array}{l}\text { Anterior } \\
\text { Chamber.. } \\
\text { Plasma } \quad .\end{array}$ & $\begin{array}{l}-0.01 \\
-0.06\end{array}$ & $\begin{array}{l}-0 \cdot 10 \\
-0 \cdot 15\end{array}$ & $\begin{array}{l}-0.09 \\
-0.04\end{array}$ & $\begin{array}{l}-0 \cdot 12 \\
-0 \cdot 16\end{array}$ & $\begin{array}{l}-0 \cdot 17 \\
-0 \cdot 24\end{array}$ & $\begin{array}{l}-0 \cdot 10 \\
-0.08\end{array}$ \\
\hline \multirow[t]{2}{*}{$\mathrm{pCO}_{2}$} & $\begin{array}{l}\text { Anterior } \\
\text { Chamber. . }\end{array}$ & $0 \pm 1 \cdot 7$ & $\stackrel{* *}{+9} \cdot 4 \pm 1 \cdot 9$ & $+1 \cdot 7 \pm 1 \cdot 3$ & $+3 \cdot 0 \pm 1 \cdot 6$ & $\stackrel{* *}{+7 \cdot 2} \pm 2 \cdot 1$ & $+3 \cdot 2 \pm 1 \cdot 6$ \\
\hline & Plasma & $+1 \cdot 0 \pm 0 \cdot 8$ & $\begin{array}{l}* * \\
+8 \cdot 7\end{array} \pm 2 \cdot 1$ & $+0.5 \pm 0.7$ & $+3 \cdot 4 \pm 1 \cdot 5$ & $+\stackrel{* *}{10 \cdot 3} \pm 2 \cdot 5$ & $+2 \cdot 1 \pm 1 \cdot 4$ \\
\hline
\end{tabular}

Values differing significantly from zero are indicated by asterisks; the range $0.05>P>0.01$ is shown by ${ }^{*}$, and the range $0.01>P$ by ${ }^{* *}$. 
TABLE IV

COMPARISON OF ELECTROLYTE AND GLUCOSE OR MANNITOL CONCENTRATION DIFFERENCES BETWEEN AQUEOUS AND PLASMA WATER

The figures represent the mean values and their standard errors

\begin{tabular}{|c|c|c|c|c|}
\hline \multicolumn{3}{|c|}{ Series } & $\begin{array}{c}\text { Sum of Concentration } \\
\text { Differences of } \mathrm{Na}, \mathrm{Cl} \text {, and } \\
\mathrm{HCO}_{3} \text { between Aqueous } \\
\text { and Plasma Water } \\
\left(\mathrm{c}_{\mathrm{a}}-\mathrm{c}_{\mathrm{p}}\right)\end{array}$ & $\begin{array}{c}\text { Concentration Difference } \\
\text { of Glucose (or Mannitol) } \\
\text { between Plasma Water } \\
\text { and Aqueous } \\
\left(c_{p}-c_{a}\right)\end{array}$ \\
\hline \multicolumn{2}{|l|}{ Unanaesthetized } & . & $-1 \cdot 7 \pm 1 \cdot 0$ & $+0.5 \pm 0.3$ \\
\hline \multicolumn{2}{|l|}{ Anaesthetized } & . & $-1 \cdot 5 \pm 1 \cdot 1$ & $+0.8 \pm 0.4$ \\
\hline \multicolumn{2}{|c|}{ Renal Vessels Ligated } & . & $-2 \cdot 6 \pm 1 \cdot 9$ & $+1 \cdot 5 \pm 0 \cdot 7$ \\
\hline \multicolumn{2}{|c|}{ Mannitol Infusion .. } & .. & $+53 \cdot 8 \pm 5 \cdot 5$ & $+54.9 \pm 5.9$ \\
\hline \multicolumn{2}{|c|}{ Intraperitoneal Glucose } & . & $+7 \cdot 4 \pm 1 \cdot 4$ & $+2 \cdot 4 \pm 1 \cdot 7$ \\
\hline \multirow{3}{*}{$\begin{array}{l}\text { Hyptonic Saline } \\
\text { Infusion }\end{array}$} & $60 \mathrm{~min}$. & . & $+8 \cdot 8 \pm 4 \cdot 9$ & $-7 \cdot 2 \pm 3 \cdot 8$ \\
\hline & $180 \mathrm{~min}$. & . & $+10 \cdot 5 \pm 5 \cdot 8$ & $\div 10.9 \pm 4.9$ \\
\hline & + DNP & $\cdots$ & $+12 \cdot 2 \pm 7 \cdot 7$ & $\pm 10 \cdot 7 \pm 5 \cdot 4$ \\
\hline
\end{tabular}

TABLE V

RELATIONSHIP BETWEEN ARTERIAL BLOOD PRESSURE (x) AND I.O.P. (y)

Both the correlation coefficient ( $r)$ and the regression of $y$ upon $x,\left(b_{y . x}\right)$ are given

In the second series (mannitol infusions) the mean fall of $29.2 \mathrm{~mm}$. $\mathrm{Hg}$ in the blood pressure is known and the corresponding fall in intra-ocular pressure is estimated from $\Delta \mathrm{y}=\mathrm{b} . \Delta \mathrm{x}$

\begin{tabular}{|c|c|c|c|c|c|}
\hline \multicolumn{3}{|c|}{ Series } & \multirow{2}{*}{$\begin{array}{c}r \\
+0.044\end{array}$} & \multirow{2}{*}{$\frac{b_{y . x}}{+0.021 \pm 0.08}$} & \multirow{2}{*}{$\begin{array}{l}\Delta y \text { (where } r \text { is } \\
\text { significant only) } \\
(\mathrm{mm} . \mathrm{Hg})\end{array}$} \\
\hline Control .. & $\cdots$ & . & & & \\
\hline Mannitol Infusion & . & . & $+0 \cdot 353^{*}$ & $+0.093 \pm 0.031^{*}$ & $-2 \cdot 72 \pm 0 \cdot 7^{* *}$ \\
\hline \multicolumn{2}{|c|}{ Intraperitoneal Glucose } & . & $+0 \cdot 171$ & $+0.03 \pm 0.02$ & \\
\hline \multirow{3}{*}{$\begin{array}{l}\text { Hypotonic Saline } \\
\text { Infusion }\end{array}$} & $60 \mathrm{~min}$. & . & $+0 \cdot 152$ & $+0.034 \pm 0.041$ & \\
\hline & $180 \mathrm{~min}$. & $\cdots$ & +0.235 & $+0.069 \pm 0.036$ & \\
\hline & $+\mathrm{DNP}$ & . & +0.068 & $+0.057 \pm 0.167$ & \\
\hline
\end{tabular}

Values differing significantly from zero are indicated by asterisks; the range $0.05>P>0.01$ is shown by ${ }^{*}$ and the range $0.01>P$ by $* *$.

Intra-Ocular Pressure.-Except in the animals given mannitol, the decrease in sodium and chloride concentration in the plasma was associated with a rise in I.O.P. Mannitol caused a fall in arterial blood pressure which showed a significant correlation with the I.O.P., and this relationship can account for about half the observed fall in I.O.P. (Fig. 1, opposite). Although in the other groups considerable changes in blood pressure were observed, they were not significantly correlated with the I.O.P. changes. 


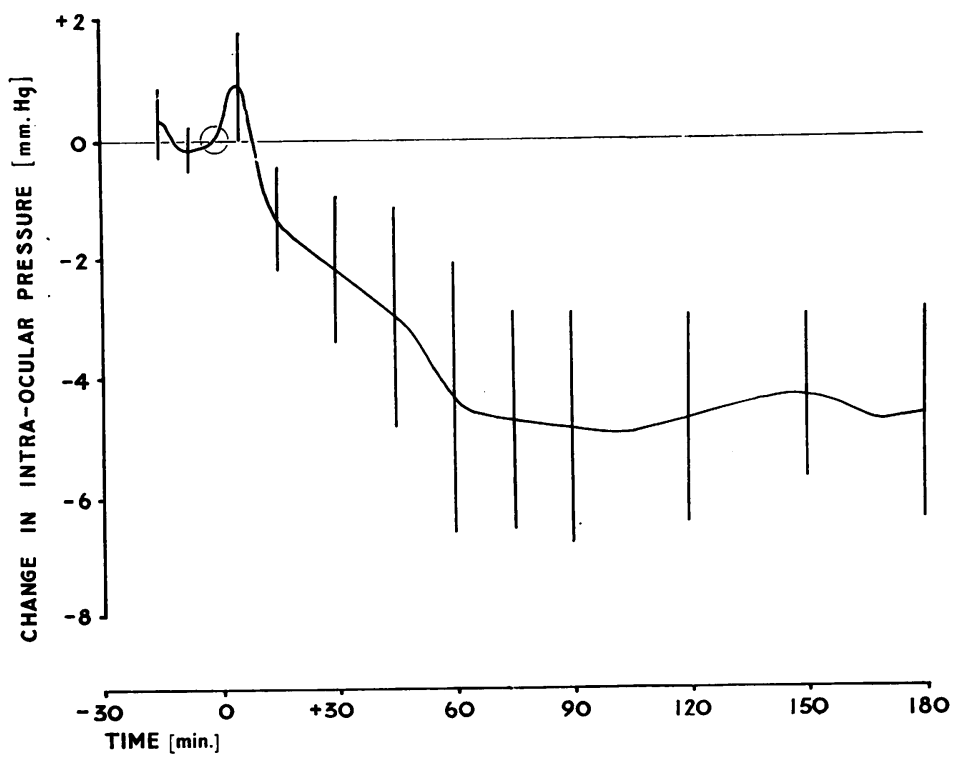

FIG. 1.-Changes in intra-ocular pressure after intravenous infusion of isotonic mannitol commencing at $\mathbf{t}=\mathbf{0}$. Continuous curve connects all points representing the mean of the differences between the I.O.P. at each 15 or 30-min. time-interval and the I.O.P. at $t=0$. Vertical lines represent $\pm 2 \times$ the standard error of the mean.

When the plasma sodium concentration decreased rapidly after infusion of hypotonic saline, the I.O.P. started to rise within $15 \mathrm{~min}$. and the increase persisted for more than 3 hours (Fig. 2).

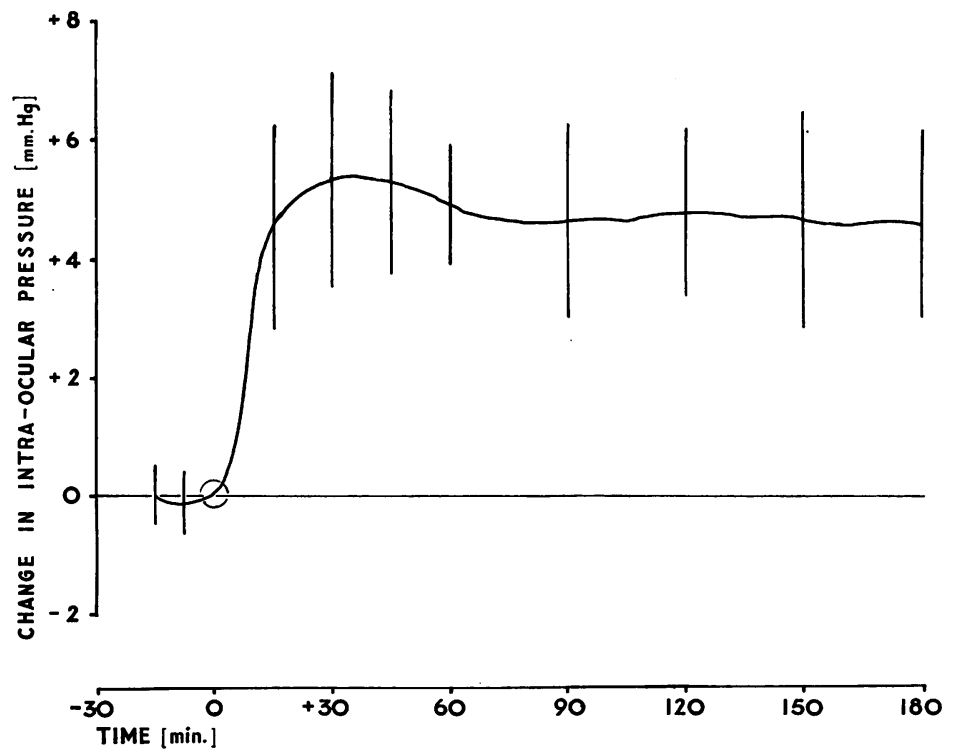

FIG. 2.-Changes in intra-ocular pressure after intravenous infusion of half-isotonic saline $(4.0 \mathrm{ml} . / \mathrm{min} . / \mathrm{kg}$. body $\mathrm{wt})$ commencing at $\mathrm{t}=0$. 
When the plasma sodium concentration decreased more slowly, after intraperitoneal injection of glucose, the increase in I.O.P. was correspondingly slower (Fig. 3).

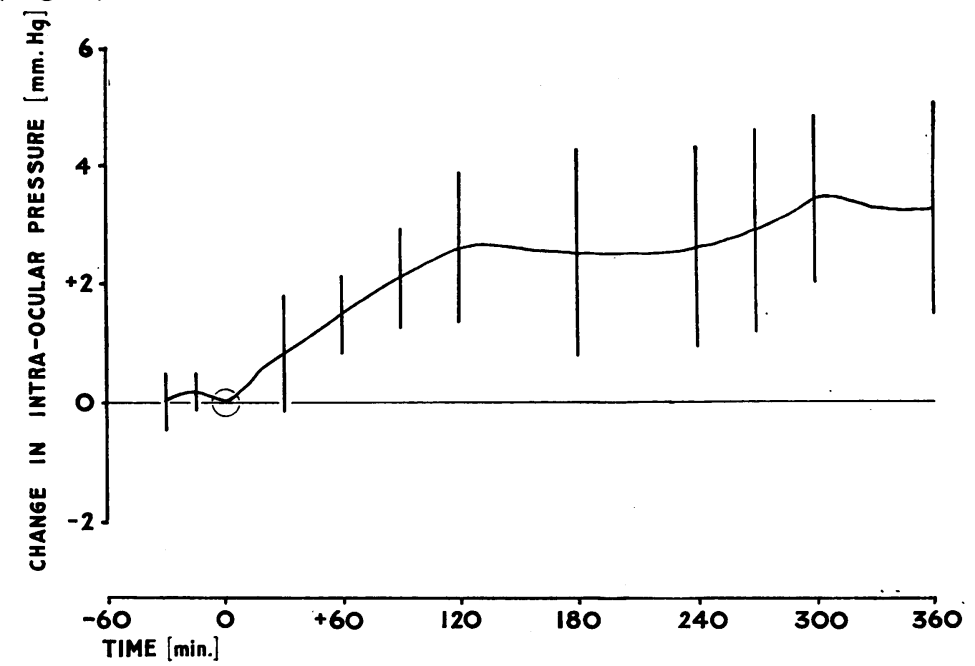

FIG. 3.-Changes in intra-ocular pressure after intraperitoneal injection of isotonic glucose given at $t=0$. Continuous curve connects all points representing the mean of the differences between the I.O.P. at each 30 or 60 -min. time-interval and the I.O.P. at $t=0$.

Vertical lines represent $\pm 2 \times$ the standard error of the mean.

The raised I.O.P. caused by hypotonic infusion decreased very markedly after intracarotid infusion of DNP, the final I.O.P. in these experiments being less than at the outset (Fig. 4, opposite).

Electrolytes.-The plasma sodium and chloride concentrations decreased to about the same extent in the mannitol, glucose, and hypotonic saline groups (Tables I and II), the concentration of each ion falling by about 25 to 30 per cent. As might be expected, there was a rapid initial fall after intravenous infusions of either mannitol or hypotonic saline (Fig. 5, overleaf), and a much slower rate of fall after intraperitoneal glucose. In the aqueous however, the concentrations of sodium and chloride did not change significantly after mannitol infusion, although both decreased very markedly in the other experimental groups (Table II). The reduction of concentration in the aqueous was less than in the plasma, but the animals were usually hyperglycaemic, either because of the intraperitoneal glucose injection, or because of the stress entailed by the operative procedures, and the excess of glucose in the plasma as compared with the aqueous was of approximately the same order of magnitude as the excess electrolyte concentration in the aqueous as compared with the plasma (Table IV).

The plasma $\mathrm{pCO}_{2}$ was increased during anaesthesia, and nephremphraxis caused a further increase which was accompanied by a fall in plasma $\mathrm{pH}$ 


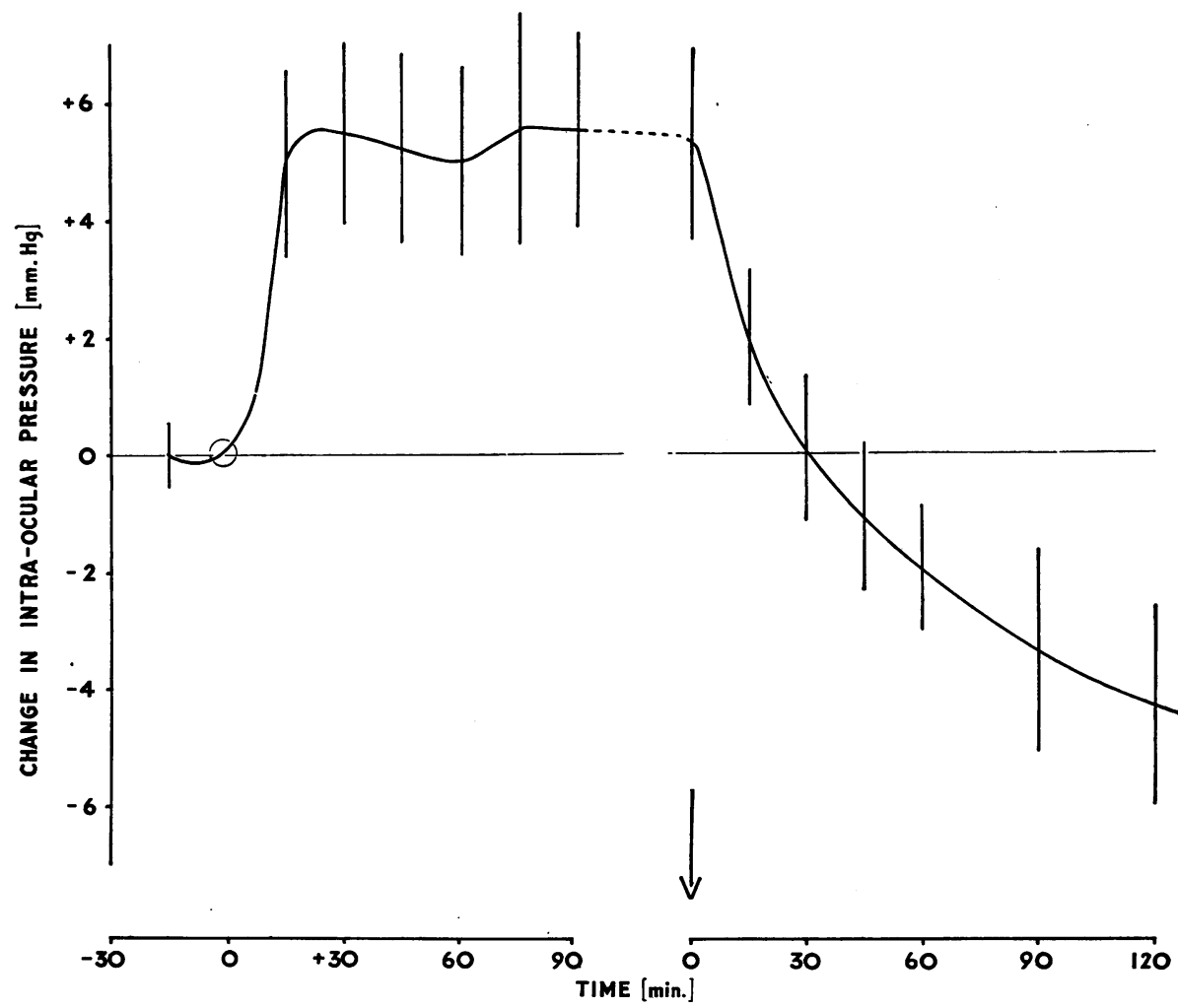

FIG. 4.-Changes in intra-ocular pressure after intravenous infusion of half-isotonic saline $(4.0 \mathrm{ml} . / \mathrm{min} . / \mathrm{kg}$. body $\mathrm{wt})$ commencing at $\mathrm{t}=0$ succeeded by intracarotid infusion of DNP at $0.11 \mathrm{mg}$. $/ \mathrm{min}$. commencing at $\mathrm{t}=0^{\prime}$.

Continuous curves connect all points representing the mean of the differences between the I.O.P. at each time-interval and the I.O.P. at $t=0$.

Broken line represents the period between $t=90$ and $t^{\prime}=0$.

Vertical lines represent $\pm 2 \times$ the standard error of the mean.

and bicarbonate. Similar changes were found in the aqueous (Tables I and II), in agreement with the observations of Langham and Lee (1957), who estimated $\mathrm{CO}_{2}$ and $\mathrm{pH}$ in whole blood and aqueous. When comparing the group means, as in Table I, rabbits after nephremphraxis are to be compared with the mannitol and hypotonic saline groups, and the unanaesthetized animals with the intraperitoneal glucose group.

Turning now to the changes during the infusion or injection, there was nearly always a fall in plasma $\mathrm{pH}$ and bicarbonate, although a significant rise in $\mathrm{pCO}_{2}$ was observed only in the glucose group and the group given DNP (Table III). The $\mathrm{pH}$ and bicarbonate concentration of the aqueous always exceeded the plasma concentrations and in most animals the ratio: $\frac{\text { aqueous concentration }}{\text { plasma concentration }}\left(c_{a} / c_{p}\right)$ (Table II), tended to increase during the 


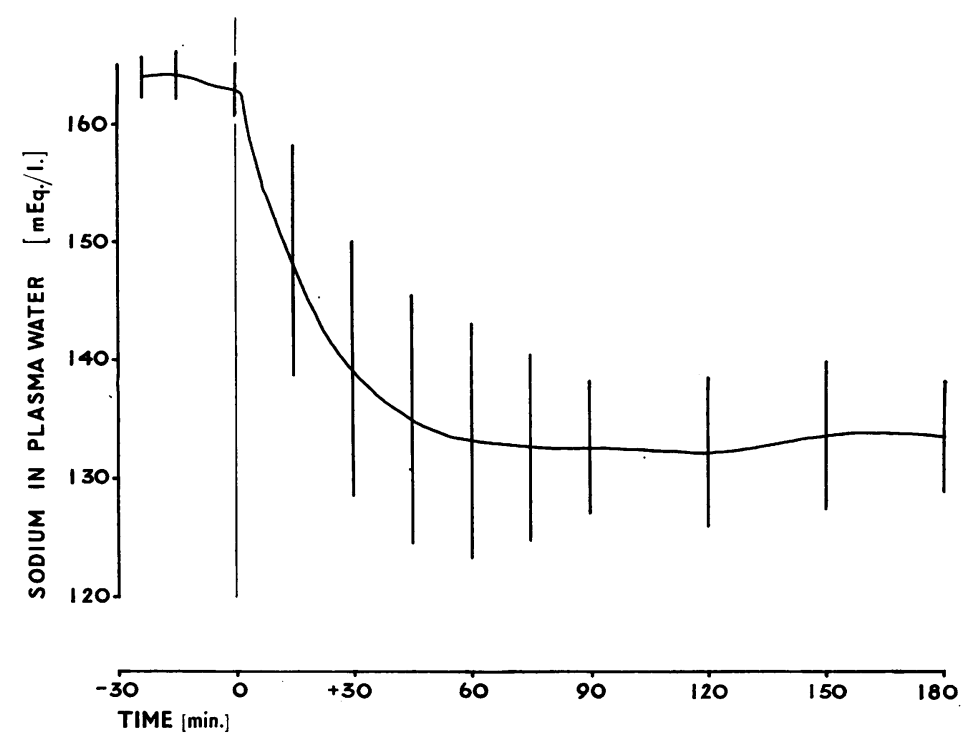

FIG. 5.-Sodium concentrations in plasma water $(\mathrm{mEq} / \mathrm{l}$.) after intravenous infusion of halfisotonic saline at $\mathrm{t}=0$.

Continuous curve connects all points representing the mean value of the sodium concentration at each time interval.

Vertical lines represent $\pm 2 \times$ the standard error of the mean.

experiment. Bicarbonate concentration and $\mathrm{pH}$ of the aqueous decreased significantly only in the glucose and DNP groups (Table III), but even here an excess of bicarbonate in the aqueous was maintained in the face of a fall in the plasma concentration (Table I). $\mathrm{pCO}_{2}$, on the other hand, did not differ significantly between plasma and aqueous.

Glucose Mannitol.-The renal vessels having been tied, the mannitol concentration in the plasma remained almost unaltered after the first $15 \mathrm{~min}$., but as it entered the aqueous slowly, after 3 hours the ratio $c_{a} / c_{p}$ was equal to $0 \cdot 145 \pm 0 \cdot 04$ (Table I). Rosner and Bellows (1939) showed that sorbitol penetrated slowly, and it is reasonable to suppose that mannitol behaves similarly. A few values for $c_{a} / c_{p}$ for intervals other than 3 hours were obtained, and an estimated steady-state ratio $\left(R_{a p}\right)$ of $0.294 \pm 0.04$ with $k_{a}=0.0045 \pm 0.001$ min. $^{-1}$ gave values for $c_{a}$ which agreed reasonably well with those observed values (Fig. 6, opposite). Assuming that the plasma concentration of mannitol remained constant, these figures were used to calculate the concentration differences $\left(c_{p}-c_{a}\right)$ at different times during the experiment (Fig. 7, overleaf). The calculated value after 3 hours is 54.60 $\mathrm{mM} / 1$, in good agreement with the mean experimental value of $54.92 \pm 5.9$ $\mathrm{mM} / 1$.

When glucose was given intraperitoneally, the plasma concentration rose to a mean value of $19.5 \mathrm{mM} / 1$. after $30 \mathrm{~min}$. and decreased steadily to 14.24 


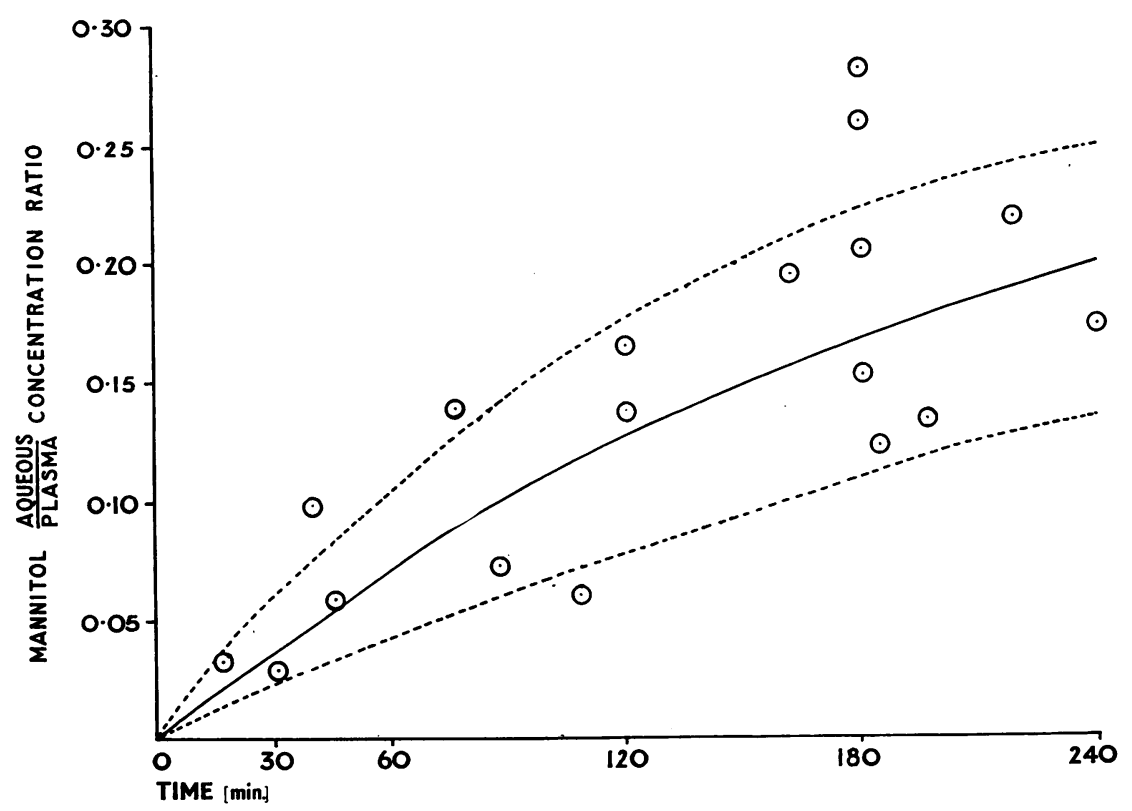

Fig. 6.-Change in $\frac{c_{a}}{c_{p}}$ for mannitol after intravenous infusion of isotonic solution at $t=0$.

Open circles represent empirical findings.

Solid line represents values calculated by assuming the steady state value of $R_{\text {ap }}$ to be $\mathbf{0 . 2 9 4}$ and $k_{a}=0.0045 \min ^{-1}$, where $\frac{c_{a}}{c_{p}}=R_{a p}\left\{e^{-k t}-1\right\}$.

Broken lines represent similar values calculated by assuming $\mathrm{k}_{\mathrm{a}}=0.0065 \mathrm{~min}^{-1}$ (upper line) and $\mathrm{k}_{\mathrm{a}}=0.0025 \mathrm{~min}^{-1}$ (lower line).

$\mathrm{mM} / 1$. after $5 \frac{1}{2}$ hours (Fig. 8, overleaf), the final concentration in the aqueous being $13.10 \mathrm{mM} / 1$. Assuming $\mathrm{k}_{\mathrm{a}}=\mathrm{k}_{\mathrm{o}} \bumpeq 0.0155 \mathrm{~min} .^{-1}$ (Davson, 1955), approximate values for $\left(c_{p}-c_{a}\right)$ after various time intervals were estimated by graphical integration (Fig. 8). The calculated concentration differences decrease rapidly during the first 3 hours, and the final value is $2.0 \mathrm{mM} / 1$, compared with the observed mean value of $2 \cdot 4 \pm 1 \cdot 7 \mathrm{mM} / 1$.

\section{Discussion}

It is commonly accepted that the continuous production of the aqueous humour is in part due to the active transport of material from the capillaries to the posterior chamber across the ciliary membrane. Friedenwald (1944, 1955) and Kinsey (1950) supposed that bicarbonate was secreted into the posterior chamber; others (Bárány, 1947; Davson, 1955; Davson and Luck, 1956), supposed sodium to be actively transported, or that anion accumulation in the posterior chamber might be the primary process (Davson and Luck, 1957). Whatever solutes are transported, the rate of exchange of water $\left(\mathrm{k}_{\mathrm{a}}^{\prime}\right)$, having a value estimated at 0.130 to $0.190 \mathrm{~min}^{-1}$ (Kinsey, Grant, and Cogan, 1942) or 0.102 min. $^{-1}$ (Friedman, Newell, LeRoy, and Okita, 1957), 


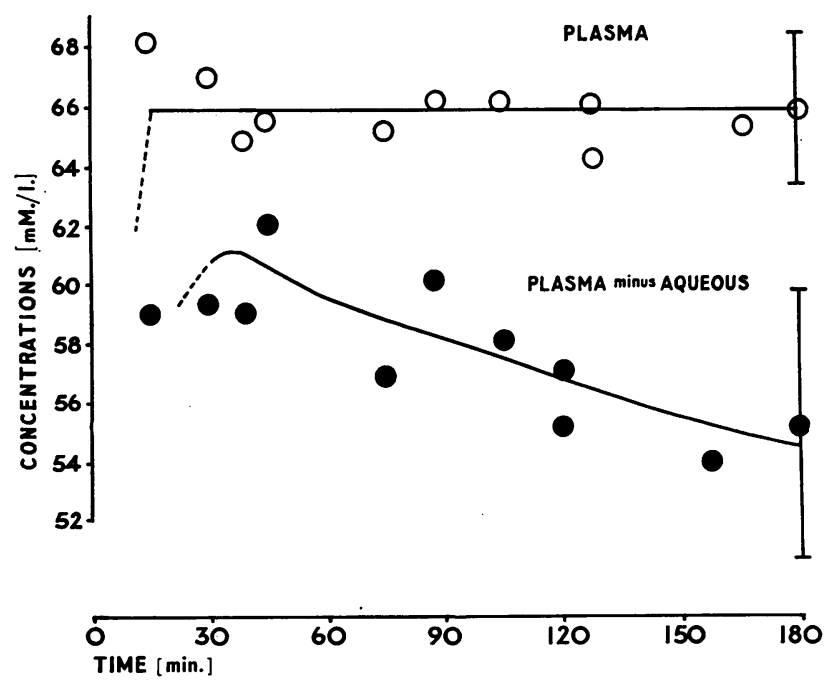

FIG. 7.-Open circles represent experimental values for concentrations of mannitol in plasma water after infusion of an isotonic solution; lower curve represents values of $c_{p}-c_{a}$ calculated by assuming $c_{p}$ to remain constant after $t=30$.

Vertical lines at $t=180$ represent $\pm 2 \times$ the standard error of the concentration in plasma water (upper line) and $\mathrm{c}_{\mathrm{p}}-\mathrm{c}_{\mathrm{a}}$ (lower line).

is considerably greater than the rate of entry of any of the ions which are supposedly secreted into the posterior chamber. Rates of entry of solutes from the posterior into the anterior chamber are derived indirectly from knowledge of the rate of water flow $\left(\mathrm{k}_{\mathrm{f}}^{\prime}\right)$ from posterior to anterior chamber, and the concentration of solute in the posterior chamber $\left(c_{h}\right)$. The value for $\mathrm{k}_{\mathrm{f}}^{\prime}$ given by Kinsey and Palm (1955) is $0.017 \mathrm{~min}^{-1}$, and from the results for the concentration of sodium and chloride in the posterior and anterior chambers of the rabbit eye given by Kinsey (1953), it may be calculated that for sodium $\mathrm{k}_{\mathrm{a} . \mathrm{ha}}=0.017 \mathrm{~min}^{-1}$, and for chloride $\mathrm{k}_{\mathrm{a} . \mathrm{ha}}=0.0162 \mathrm{~min} .^{-1}$. Davson (1955) obtained a value for $k_{f}^{\prime}$ of $0.008 \mathrm{~min}^{-1}$, from which correspondingly lower values of $\mathrm{k}_{\mathrm{ha}}$ for sodium and chloride would result. The total exchange rates also include the exchange between plasma and anterior chamber across the iris, and Kinsey and Palm (1955) give values of $\mathbf{k}_{\text {a.pa }}$ for sodium and chloride as $0.0125 \mathrm{~min}^{-1}$ and $0.0130 \mathrm{~min} .^{-1}$ respectively. Since $k_{a}=k_{a .(p+h) a}=k_{a . p a}+k_{a . h a}$, the values of $k_{a}$ for sodium and chloride, on the basis of these figures, would be 0.0292 and $0.0295 \mathrm{~min}^{-1}$ respectively, considerably less than the value for water.

Because of this more rapid rate of penetration of water, it follows that, when the osmotic concentration of the plasma is reduced compared with that of the intra-ocular fluids, water will enter the eye more rapidly until a fresh osmotic equilibrium is established, a possibility recently envisaged by Levene (1958). Because the diffusion constants of the solutes are less than that of water, the entry of water will be more important than the loss of solute in attaining the new equilibrium. A further consequence of the high exchange 


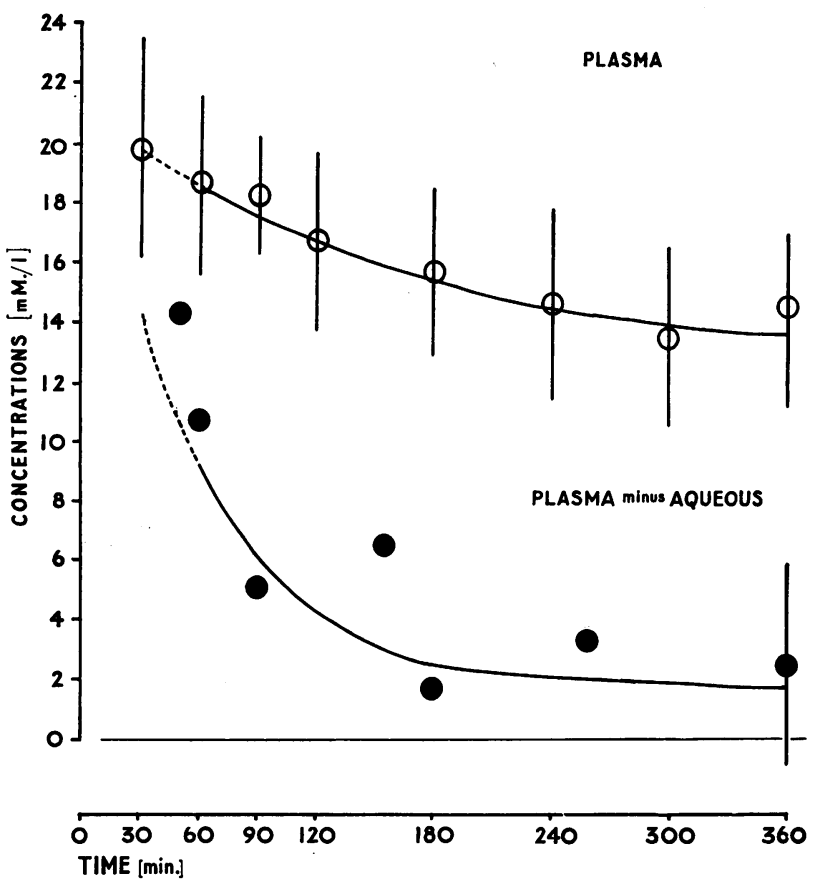

Fig. 8. - Open circles represent experimental values for plasma glucose concentration after infusion of isotonic solution.

Solid circles represent individual values for concentration in aqueous humour. Upper curve fitted by eye; lower curve represents $c_{p}-c_{a}$ calculated from changes in $c_{p}$, assuming $k_{a}=$ 0.0155 min. -1 .

Vertical lines represent $\pm 2 \times$ the standard error of the mean at various time-intervals for the plasma concentration, and at $t=360$ for $c_{p}-c_{a}$ determined experimentally.

rate of water is that, where a solute is actively secreted into the posterior chamber, water may enter sufficiently rapidly to ensure that the osmotic concentration of the aqueous is little, if indeed at all, greater than that of the plasma. The actual rate of entry of fluid, insofar as it is caused by secretion of a solute, will depend on the rate of solute transport into the eye and on the osmotic concentration of the plasma.

If the further assumption is made that the rate of transport of the solute into the posterior chamber $\left(\frac{\mathrm{dm}_{\mathrm{ph}}}{\mathrm{dt}}\right)$ is independent of its concentration in the plasma, it is possible to give a general explanation of the present experimental findings. After the infusion of hypotonic saline, the osmotic concentration of the plasma is reduced, water enters the eye at an increased rate, and the concentration of sodium and chloride in the aqueous falls. After intraperitoneal injection of glucose, the sodium concentration of the plasma also falls, and, as glucose enters the aqueous, the increased concentration of this substance in the plasma does not effectively restrict the nett entry of water. Hence, as in the hypotonic infusions, more water (accompanied in this case 
by glucose) enters the eye, and, as before, the sodium and chloride concentrations of the aqueous decrease. When, on the other hand, the concentration of sodium in the plasma is reduced by infusion of isotonic mannitol, the mannitol enters the aqueous very much more slowly than the glucose, and the difference in concentration between plasma and aqueous which is due to the mannitol suffices to prevent an increase in the nett rate of entry of water. In accordance with this view there is a rise in I.O.P., indicating increased entry of water, and a fall in electrolyte concentrations only in those animals given hypotonic infusions or intraperitoneal glucose; whereas, in those given isotonic mannitol, there is neither a rise in I.O.P. nor a decrease in electrolyte concentrations. It is noteworthy that in all the groups the sum of the values of $\left(c_{a}-c_{p}\right)$ for sodium, chloride, and bicarbonate, representing the osmotic forces tending to draw water into the eye, is approximately balanced by the excess of glucose or mannitol in the plasma $\left(c_{p}-c_{a}\right)$ as shown in Table IV. Thus, although the solute distributions may have not reached a steady state, it appears that approximate osmotic equilibrium has been achieved by the rapid movement of water. This explanation is supported by the finding that, after infusion of hypotonic saline, which caused a rapid reduction of the sodium and chloride concentrations of the plasma (Fig. 5), the major increase in I.O.P. occurred during the first half hour, and the decrease in sodium and chloride concentrations in the aqueous was not greater after 3 hours than after the first hour (Table II).

If the hypothesis which has been suggested is substantially correct, the aqueous will be approximately in osmotic equilibrium with plasma, but at any given osmotic concentration of the plasma the rate of formation of aqueous in the equilibrium state will depend upon the rate of transport of solute across the ciliary epithelium into the posterior chamber. Furthermore, if water can penetrate into the eye more rapidly than any of the transported solutes, alterations in the rate of solute transport will cause changes in the nett rate of entry of fluid, rather than changes in the concentration of solutes in the aqueous. This is confirmed by comparing the results of the hypotonic infusions alone with the results of infusing DNP $90 \mathrm{~min}$. after starting the infusion of hypotonic saline. By this time the I.O.P. has increased to a stable value which, in the absence of further treatment, persists for at least $90 \mathrm{~min}$. (Fig. 2), and the major decrease in sodium and chloride concentrations in both aqueous and plasma has already occurred (Table II; Fig. 5). The stability of the I.O.P. indicates an increased rate of aqueous formation which persists after the initial stages of equilibrium of the eye with reduced solute concentration of the plasma. After 3 hours there is no significant difference between the posterior and anterior chambers and no indication of a nett influx of water from the iris vessels; but because the I.O.P. remains high it is inferred that the total rate of formation of aqueous remains high also, because of an increased rate of production of fluid in the posterior chamber. This in turn is explained in the present hypothesis on the assump- 
tion that solutes are transported into the posterior chamber at a constant rate throughout the whole experiment, but that, when the osmotic concentration of the plasma is reduced, more water is free to diffuse across the ciliary epithelium. Consequently, the posterior chamber as a whole will produce a more dilute fluid at an increased rate, even in the steady state.

It is unlikely that an equilibrium condition was reached in any of these experiments, as the exchange rates of sodium in the vitreous and other tissues surrounding the aqueous are slower than those between aqueous and plasma (Kinsey and Palm, 1955; Maurice, 1957). An hour after starting the hypotonic infusions, there was evidence of a considerable nett gain of water, or loss of sodium, by the anterior chamber, $c_{a}$ being $8.0 \pm 2.02 \mathrm{mEq} / \mathrm{l}$. less than $\mathrm{c}_{\mathrm{h}}$. On the assumption that a solute is transported into the posterior chamber at a constant rate $\left(\frac{\mathrm{dm}_{\mathrm{ph}}}{\mathrm{dt}}\right)$ and leaves it at the same rate $\left(\frac{\mathrm{dm}_{\mathrm{ha}}=\mathrm{dm}_{\mathrm{ph}}}{\mathrm{dt}}\right)$, and that the initial value of $\mathrm{k}_{\mathrm{f}}^{\prime}$ was $0.017 \mathrm{~min}^{-1}$, the decrease in $\mathrm{c}_{\mathrm{h}}$ necessitates an increased rate of flow from the posterior chamber in order that $\frac{\mathrm{dm}_{\text {ha }}}{\mathrm{dt}}$ remain unaltered. According to the figures in Tables I and II, the value of $\mathrm{k}_{\mathrm{f}}^{\prime}$ after $60 \mathrm{~min}$. would be $0.0183 \mathrm{~min} .^{-1}$. However, if it is accepted that for water $\mathrm{k}_{\mathrm{a}}=0.130 \mathrm{~min}^{-1}$, then the exchange rate for water across the iris $\left(\mathrm{k}_{\mathrm{a} . \mathrm{pa}}^{\prime}\right)$ remains greater than $0 \cdot 100$ min. $^{-1}$. For sodium and chloride, on the other hand, $\mathrm{k}_{\mathrm{a} . \mathrm{pa}}$ is unlikely to exceed $0.013 \mathrm{~min}^{-1}$ (Kinsey and Palm, 1955), and it therefore seems most likely that, there being a decrease in plasma osmolarity, the low value of $c_{a}$ is due to nett entry of water which occurs much more rapidly than nett sodium loss. If the nett sodium loss is negligible, then $\mathrm{k}_{\mathrm{o}}^{\prime} \mathrm{c}_{\mathrm{a}}=\mathrm{k}_{\mathrm{f}} \mathrm{c}_{\mathrm{h}}$, and $\mathrm{k}_{\mathrm{o}}^{\prime}=0.0194 \mathrm{~min} .^{-1}$, or $5.82 \mu \mathrm{l} . / \mathrm{min}$. in an eye having an aqueous volume of $300 \mu 1$. (cf Maurice, 1957). This would represent a nett entrance of $0.33 \mu \mathrm{l} . / \mathrm{min}$. into the anterior chamber by iris diffusion, and an increase in flow from the posterior chamber from $5 \cdot 1$ to $5.49 \mu 1$./ min. According to this method of estimating $\mathbf{k}_{\mathrm{f}}^{\prime}$, after 3 hours' infusion of hypotonic saline or after intraperitoneal glucose, the flow would have increased by about 10 per cent., which would not be attributable to iris diffusion, but rather to increased rate of formation in the posterior chamber.

2, 4: dinitrophenol (DNP) is known to depress the activity of a number of tissues which normally transport sodium ion $(\mathrm{Na} \cdot)$ actively against an electrochemical gradient. DNP inhibits $\mathrm{Na} \cdot$ transport in frog skin (Fuhrman, 1952; Schoffeniels, 1955) and in frog renal tubules (Hoshiko, Swanson and Visscher, 1956) and potassium accumulation and sodium extrusion in chicken erythrocytes (Maizels, 1954) and mammalian kidney slices (Mudge, 1951); it was used in the present experiments in an attempt to cause inhibition of electrolyte transport across the ciliary membrane. DNP was infused into the lingual artery at a rate of $0.11 \mathrm{mg}$./min. which, assuming the carotid blood flow to be about $3 \mathrm{ml} . / \mathrm{min}$. (calculated from the data of Winterstein, 1935), would yield a plasma concentration of DNP of $0 \cdot 2-0.3 \mathrm{mM} / 1$. 
There was a marked fall in I.O.P., commencing as soon as the infusion was started (Fig. 4), the final I.O.P. being significantly less than the value at the start of the experiments. The sodium, chloride, and bicarbonate concentrations in the anterior aqueous after DNP did not differ from those seen in animals after hypotonic saline infusion alone, and the low value $(133 \cdot 9 \pm 2 \cdot 3$ $\mathrm{mEq} / \mathrm{l}$.) in the posterior chamber was probably due to the fact that the final concentration of sodium in the plasma water was lower in this group than in the others (Table I). The ratio $c_{a} / c_{p}$ for anterior and posterior chamber aqueous did not differ from those found in animals given hypotonic saline only. This dose level of DNP can be said to have caused a severe fall in I.O.P. with no apparent alteration in the electrolyte concentrations in the aqueous; this is in agreement with the hypothesis that the inhibition of ion transport causes a decreased rate of entry of water into the posterior chamber rather than a change in composition of the aqueous.

These findings do not indicate what particular transport process is inactivated by DNP, any system directly or indirectly dependent upon oxidative phosphorylation being subject to inhibition. The effects of DNP are probably similar to the results described by Ballintine and Peters (1954); Ballintine and Weitzman (1956), who produced a reduction in I.O.P. by inhibition of oxidative phosphorylation with cyanine and styryl-quinoline dyes, have demonstrated oxidative phosphorylation in the ciliary processes of the rabbit in vitro.

These experiments show the importance of an active transport system and of osmotic diffusion of water in maintaining the I.O.P., and they suggest that active transport is a necessary requirement, but that hypertonicity of the fluids may be restricted to a very small zone near the secreting epithelium. They also suggest that aqueous concentrations, or values of $r_{a p}$ taken by themselves, give only limited information about the entrance of solutes from the plasma into the aqueous humour.

\section{Summary}

The plasma sodium concentration in rabbits was reduced either by expanding the extracellular space with isotonic mannitol, or by infusing hypotonic saline, or by peritoneal dialysis against isotonic glucose solution.

When the plasma sodium concentration was reduced without reducing the osmolarity of the plasma (as in the mannitol experiments), then the sodium and chloride concentrations of the aqueous showed very little change although the intra-ocular pressure decreased.

When plasma osmolarity as well as the sodium concentration was reduced (after hypotonic infusions or peritoneal dialysis), then the concentrations of sodium, chloride and bicarbonate in the aqueous also decreased and the I.O.P. showed an increase which lasted for several hours.

If 2, 4: dinitrophenol was infused after this elevation of I.O.P. had occurred, 
there was an abrupt decrease of pressure but little change of electrolyte concentration in the aqueous humour.

It is suggested that water enters the eye sufficiently rapidly to ensure that the aqueous is approximately iso-osmotic with the plasma, and that the transport of solute into the posterior chamber is unaffected by reducing the concentration of sodium in the plasma. The nett rate of entry of fluid into the posterior chamber will then depend upon both the rate of transport of solute and upon the osmolarity of the plasma.

\section{REFERENCES}

Ballintine, E. J., and Peters, L. (1954). Amer. J. Ophthal., 38 (July: pt II), 153. and WAITZMAN, M. (1956). Ibid., 42 (October: pt II), 349.

BÁRÁNY, E. H. (1947). Acta physiol. scand., 13, 55.

DARROW, D. C., and YANNET, H. (1935). J. clin. Invest., 14, 266.

Davson, H. (1955). J. Physiol. (Lond.), 129, 111. and Luck, C. P. (1956). Amer. J. Ophthal., 41, 809 (1957). J. Physiol. (Lond.), 137, 279.

DUKe-Elder, S. (1926). Brit. J. Ophthal., 10, 1. (1932). "Text-book of Ophthalmology", vol. 1., p. 507. Kimpton, London. and MAURICE, D. M. (1957). Brit. J. Ophthal., 41, 702.

FRIEDENWALd, J. S. (1944). Ibid., 28, 503.

(1955). Amer. J. Ophthal., 39, (April: pt II), 59.

Friedman, M., Newell, F. W., LeRoy, G. V., and OkItA, G. T. (1957). Ibid., 44 (November), 375.

Furrman, F. A. (1952). Amer. J. Physiol., 171, 266.

Hamburger, J., RyCKewaert, A., Duizend, M., and Argant, N. (1948). Ann. Biol. clin., 6, 353.

Hertel, E. (1914). v. Graefes Arch. Ophthal., 88, 197.

Hoshiko, T., Swanson, R. E., and Visscher, M. B. (1956). Amer. J. Physiol., 184, 542.

Joels, N., and MaCNaughton, J. I. (1957). J. Physiol. (Lond.), 135, 1P.

KINSEY, V. E. (1950). Arch. Ophthal. (Chicago), 44, 215. (1953). A.M.A. Arch. Ophthal., 50, 401. , Grant, M., and Cogan, D. G. (1942). Arch. Ophthal. (Chicago), 27, 242. and Palm, E. (1955). A.M.A. Arch. Ophthal., 53, 330.

LANGhaM, M. E., and LeE, P. M. (1957). Brit. J. Ophthal., 41, 65.

LeVene, R. Z. (1958). A.M.A. Arch. Ophthal., 59, 597.

Maizels. M. (1954). J. Physiol. (Lond.), 125, 263.

MAURICE, D. M. (1957). Ibid., 137, 110.

Milch, R. A., BANE, H. N., and Roberts, K. E. (1957). J. appl. Physiol., 10, 151.

Mudge, G. H. (1951). Amer. J. Physiol., 167, 206.

Natelson, S. (1951). Amer. J. clin. Path., 21, 1153.

Phillirs, R. A., Van Slyke, D. D., Dole, V. P., Emerson, K., Hamilton, P. B., and ArChibald, R. M. (1945). "Copper Sulphate Method for determining the Specific Gravity of Whole Blood and Plasma." Josiah Macy (Jr.) Foundation, New York.

Rosner, L., and Bellows, J. (1939). Amer. J. Physiol., 125, 652.

SCHOFFENIELS, E. (1955). Arch. intern. Physiol., 63, 361.

SOMOGYI, M. (1945a). J. biol. chem., 160, 61. (1945b). Ibid., 160, 69.

Sunderman, F. W., and Boerner, F. (1949). "Normal Values in Clinical Medicine”, p. 94. Saunders, Philadelphia.

WeEkERS, L. (1924). Arch. Ophtal., 41, 65.

Winterstein, H. (1935). Pflüg. Arch. ges. Physiol., 235, 377. 